\title{
Should compression bandage be performed after total knee arthroplasty? A meta-analysis of randomized controlled trials
}

\author{
Pei Liu', Xiaohong $\mathrm{Mu}^{2}$, Qidong Zhang ${ }^{3}$, Zhaohui Liư ${ }^{3}$, Weiguo Wang ${ }^{3^{*}}$ and Wanshou Guo ${ }^{3^{*}}$ (D)
}

\begin{abstract}
Background: Compression bandage often is used after total knee arthroplasty (TKA) to alleviate pain, ameliorate swelling, and reduce bleeding. However, there is controversy about its application due to conflicting clinical outcomes and potential compression-related complications. This meta-analysis aimed to answer the question of if compression bandage should be implemented routinely after TKA.

Methods: Relevant randomized controlled trials (RCTs) on compression bandage were comprehensively retrieved utilizing search engines such as PubMed, EMBASE, Web of Science, and the Cochrane Library, up to September 2019. Studies included in the meta-analysis were those that compared post-operative pain score, swelling, total blood loss, pre- and post-operative hematocrit levels differences, range of motion (ROM), and complications, using Review Manager 5.3.0.

Results: Included were seven RCTs, which reported on 511 knees. The pooled results showed the compression bandage group was associated with a greater post-operative pain score during ambulation at $48 \mathrm{~h}(\mathrm{WMD}=0.70,95 \% \mathrm{Cl} 0.07$ to $1.34, P=0.03)$, compared with the non-compression bandage group. No statistically significant differences were found between the groups in post-operative pain scores at the other times, swelling, blood loss, ROM, or other complications $(P>0.05)$.

Conclusions: The current evidence is unable to conclude that compression bandage is necessary after primary TKA. Surgeons routinely undertaking compression bandage should deliberate whether there is enough clinical evidence.
\end{abstract}

Keywords: Compression bandage, Total knee arthroplasty, Meta-analysis

\section{Introduction}

Total knee arthroplasty (TKA) is a safe and effective procedure for the alleviation of pain, correction of deformity, and restoration of knee function to patients with symptomatic end-stage knee osteoarthritis [1]. However, post-operative pain, swelling, and inflammation in the perioperative tissues can cause many adverse events. This includes increased wound

\footnotetext{
* Correspondence: wangweiguo@zryhyy.com.cn; wanshoug@sina.com ${ }^{3}$ Department of Orthopaedic Surgery, Beijing Key Lab Immune-Mediated Inflammatory Diseases, China-Japan Friendship Hospital, Yinghuadong Road, Chaoyang District, Beijing, China

Full list of author information is available at the end of the article
}

complications, impaired knee-extension strength, slower rehabilitation, prolonged hospitalization, and even the potential risk of mortality and morbidity [2-4]. Many strategies have been investigated in attempt to manage complications, which include minimally invasive procedures, without intraoperative tourniquet utilization, intra-articular injection of tranexamic acid and/or corticosteroid, cryotherapy, immobilization, compression bandage technique, and elevation of the affected limb [5-8].

The application of compression bandages from toes to mid-thigh is common following TKA [9], with authors reporting that the compression bandages 
limited pain by immobilization of the affected area, ameliorated soft tissue swelling by helping lower limb venous reflux, and reduced post-operative bleeding by compressing capillaries [10-12]. However, a number of studies have shown no difference in the levels of pain, swelling, blood loss, or range of motion (ROM) after surgery when comparing the use of compression bandages with non-compression bandages [13-15]. Furthermore, the use of compression bandages may even induces further detrimental effects directly linked to the compression such as discomfort, peroneal nerve paralysis, pressure ulcers, bruising, dermal blisters, and therefore additional costs [16-18].

The clinical outcomes on whether or not the use of compression bandages is advantageous in TKA recovery have been compared in previous randomized controlled trials (RCTs); however, they have been limited by small sample sizes and heterogeneous methodology. Therefore, the aim of this research was to reevaluate the efficacy and safety of compression bandages for use in primary TKA post-operative care using meta-analysis methods.

\section{Methods}

This meta-analysis was carried out according to the Preferred Reporting Items for Systematic Reviews and Meta-analyses (PRISMA) checklist. No ethical approval or patient written informed consent was required.

\section{Literature search}

Articles published in English on compression bandages after primary TKA were retrieved in electronic databases. Databases used were PubMed, EMBASE, Web of Science, and the Cochrane Library, up to September 2019. Additionally, bibliographies of articles identified as relevant were examined further to determine any other potentially relevant studies. A structured search was implemented using the following search string: (Total Knee Arthroplasty OR Total Knee Replacement) AND (Compression Bandage OR Modified Robert Jones Bandage OR Compression Therapy OR Compression Dressing) AND (Randomized controlled trials OR Random OR Blind). The search did not cover restrictions regarding publication time.

\section{Inclusion and exclusion criteria}

RCTs were selected for the meta-analysis if the following criteria were met. Criteria included population, intervention, comparison, outcome, and study design (PICOS). Population: patients had an existing diagnosis of knee osteoarthritis and were prepared for primary TKA. Intervention: compression bandage of lower limbs. Comparison: placebo or conventional wound dressing after TKA. Outcomes: post-operative pain score, swelling, total blood loss, pre- and postoperative hematocrit levels differences, ROM, and complications. Study design: RCTs.

If any of the following was present in the study (non-conformance to inclusion criteria, low-quality RCTs and non-RCTs, conference abstracts and duplicates, undefined samples or grouping, nontherapeutic clinical studies, non-original studies, case reports, and non-full-data analysis), the study was excluded.

\section{Data extraction}

The following data was extracted from trials (author's name, year of publication, sample size, age, gender, body mass index (BMI), intervention, control group, outcomes, study design, and follow-up duration), using a standard data extraction form. As well, relevant data was extracted independently by two authors (Xiaohong $\mathrm{Mu}$ and Qidong Zhang). In studies where data was incomplete, missing, or unclear, attempts were made to contact the authors for further clarification.

\section{Assessment of methodological quality}

Two reviewers (Zhaohui Liu and Qidong Zhang) independently determined the method quality regarding bias in the selected studies (in accordance with the Cochrane Handbook for Systematic Reviews of Interventions). Methods included in the bias assessment were random sequence generation, allocation sequence concealment, blinding of participants and outcome assessors, incomplete outcome data, reporting bias, and other bias. Subsequently, each item was scored as "yes" (low risk of bias), "unclear" (unclear risk of bias), or "no" (high risk of bias). Discrepancies were then cross-checked and resolved by a third reviewer (Weiguo Wang), of which only then was a final consensus reached. A risk-of-bias summary and risk-of-bias graph was then generated using Review Manager 5.3.0 software (Nordic Cochrane Centre, Cochrane Collaboration, Copenhagen, Denmark).

\section{Statistical analysis}

The results of eligible studies were pooled for metaanalysis when two or more results were available. Continuous variables were entered as means and standard deviations, and dichotomous outcomes as the number of events. Continuous outcomes were expressed as weighted mean differences (WMD), and dichotomous data as relative ratios (RR), and both reported to confidence intervals (CIs) of 95\% (level 
of statistical significance $P<0.05)$. A fixed-effects model was utilized if the chi-square test showed $I^{2}$ was $<50 \%$ and $P$ was $>0.1$, and this was used to estimate statistical heterogeneity. If these conditions were not met, a random-effects model was utilized. Unfortunately, publication bias was not assessed due to scant selected studies.

\section{Results}

\section{Search results}

Initially, a total of 403 pertinent studies were identified with our search strategy, as well as an additional report found during the manual search of references. Endnote Software (Version X8, Thompson Reuters, CA, USA) detected 335 duplicate studies, thus were removed. As well, an additional 33 studies were ruled out by screening the title and abstract. Lastly, another 29 studies were excluded after reading the full text because they did not meet inclusion criteria. Therefore, only seven studies were finally selected in this meta-analysis. The PRISMA flow diagram is presented in Fig. 1.
Description of included studies and quality assessment A total of seven RCTs [13-15, 18-21] totaling 511 knees were involved in the meta-analysis. The average age was 67.6 years, length of follow-up term varied from 1 week to 6 months, and post-operative pain scores at rest and during ambulation were rated on the visual analogue scale (VAS, scored from 0 to 10). Post-operative swelling was quantified by circumference at the middle thigh, knee, and mid lower leg. Indicators of blood loss included total blood loss and pre- and post-operative hematocrit levels differences. Lastly, ROM and complications after surgery were reported in three and two studies respectively. Detailed information can be seen in Additional file 1 .

The evidence quality was evaluated using the Grading of Recommendations Assessment, Development, and Evaluation (GRADE) approach, as described in the Cochrane Handbook for Systematic Reviews of Intervention. Selection and performance bias had not been eliminated, as it was not possible to blind patients or surgeon to the intervention. However, all the

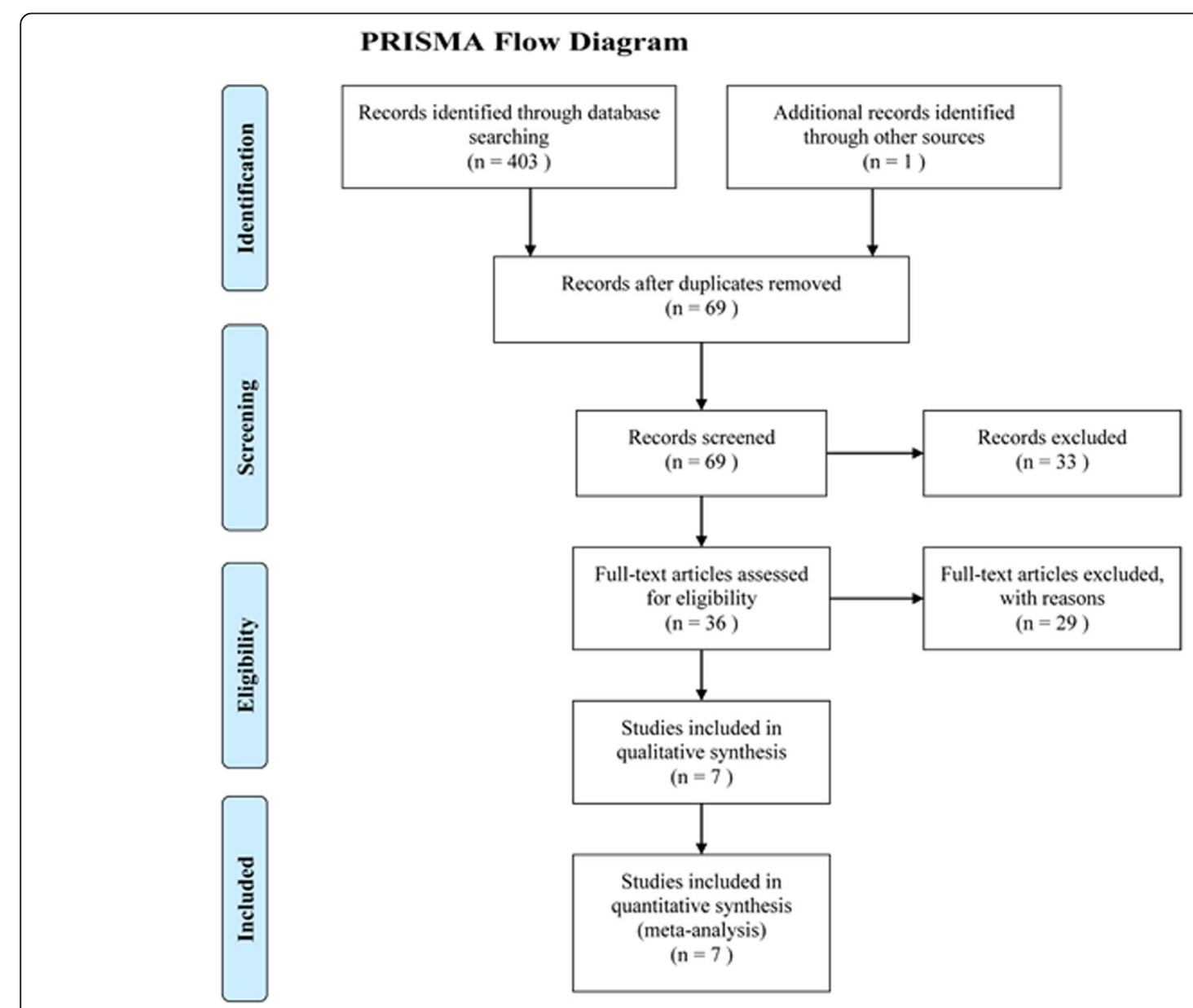

Fig. 1 Flow diagram of study search and inclusion criteria 
selected studies contained high-quality evidence with a low risk of bias Fig. 2.

\section{Results of meta-analysis Post-operative pain}

The pain score at rest was recorded at $24 \mathrm{~h}$ (five studies $[13-15,19,20]$ including 369 knees) and $48 \mathrm{~h}$ (four studies [13, 15, 19, 20] including 309 knees) postoperatively. No statistical heterogeneity was found between the compression bandage group and control group; thus a fixed-effects model was applied. Pooled results showed no significant difference in postoperative pain at $24 \mathrm{~h}(\mathrm{WMD}=0.33,95 \% \mathrm{CI}-0.12$ to $0.78, P=0.15)$ or $48 \mathrm{~h}(\mathrm{WMD}=0.36,95 \% \mathrm{CI}-0.15$ to $0.87, P=0.16)$.

Post-operative pain during ambulation was also recorded at $24 \mathrm{~h}$ (four studies $[14,15,19,20]$ including 309 knees) and $48 \mathrm{~h}$ (three studies [15, 19, 20] including 321 knees). Similarly, tests of heterogeneity showed no difference using the fixed effects model for analysis. Pooled results showed no significant difference between both group in terms of post-operative pain at $24 \mathrm{~h}$ (WMD $=0.36,95 \%$ CI -0.15 to $0.87, P=0.16$ ). However, post-operative pain at $48 \mathrm{~h}$ in the non-compression bandage group was

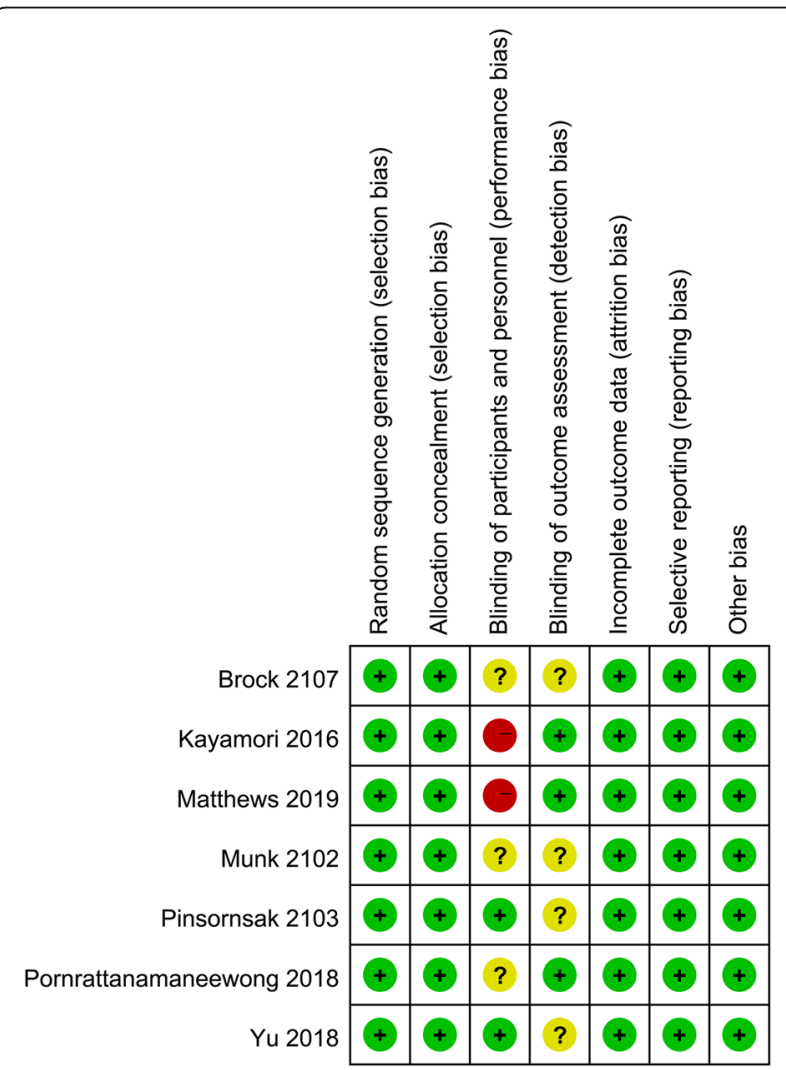

Fig. 2 Risk-of-bias summary of included randomized controlled trials. + , no bias; -, bias,? bias unknown significantly lower than in the compression bandage group (WMD $=0.70,95 \% \mathrm{CI} 0.07$ to $1.34, P=0.03$ ). The detailed information can be viewed in Fig. 3.

\section{Post-operative swelling}

We evaluated post-operative swelling quantified by the circumference at the middle thigh (four studies $[13,14,19,21]$ involving 307 knees), knee (three studies [14, 18, 19] involving 275 knees), and mid lower leg (four studies [13, 14, 18, 19] involving 335 knees). There was no significant heterogeneity between both groups, and thus, we used a fixed-effects model. No significant difference was found for circumferences at the middle thigh (WMD $=0.15,95 \%$ CI -0.92 to $1.21, P=0.79$ ), knee (WMD $=0.07,95 \%$ CI -0.83 to $0.97, P=0.87$ ), or mid lower leg (WMD = $0.04,95 \%$ CI -0.69 to $0.77, P=0.92$ ) Fig. 4 .

\section{Post-operative blood loss}

Post-operative blood loss was estimated via total blood loss (four studies [13, 14, 20, 21] with 275 knees), and pre- and post-operative hematocrit levels differences (three studies [13, 14, 20] with 218 knees). Pooled results indicated that the compression bandage group was not associated with less total blood loss (WMD $=-26.04,95 \% \mathrm{CI}-83.32$ to $31.25, P=0.37$ ) or pre- and post-operative hematocrit level differences (WMD $=-0.52,95 \% \mathrm{CI}-5.19$ to $4.15, P=0.87$ ). A fixed-effects model was applied according to statistical heterogeneity Fig. 5.

\section{Post-operative ROM}

Three of the seven RCTs [14, 19, 21] (229 knees) measured post-operative ROM in the two groups. Pooled results indicated that the use of compression bandages did not result in increasing ROM (WMD $=-26.04$, 95\% CI -83.32 to $31.25, P=0.37$ ). A fixed-effects model was applied according to statistical heterogeneity $\left(I^{2}=0 \%\right.$, $P=0.77)$ Fig. 6.

\section{Complications}

Two trials [14, 19] reported complications in a total of 190 knees. A fixed-effects model was utilized $\left(I^{2}=9 \%\right.$, $P=0.56)$. No significant difference in complications was observed between the two compared groups $(R R=0.63$, $95 \%$ CI 0.21 to $1.84, P=0.39$ ) Fig. 7.

\section{Discussion}

The most important findings observed in the presented meta-analysis are that compared with the use of non-compression bandage, the use of compression bandage after primary TKA generates no additional clinical benefits. Our pooled data found that the use of a non-compression bandage actually showed lower 


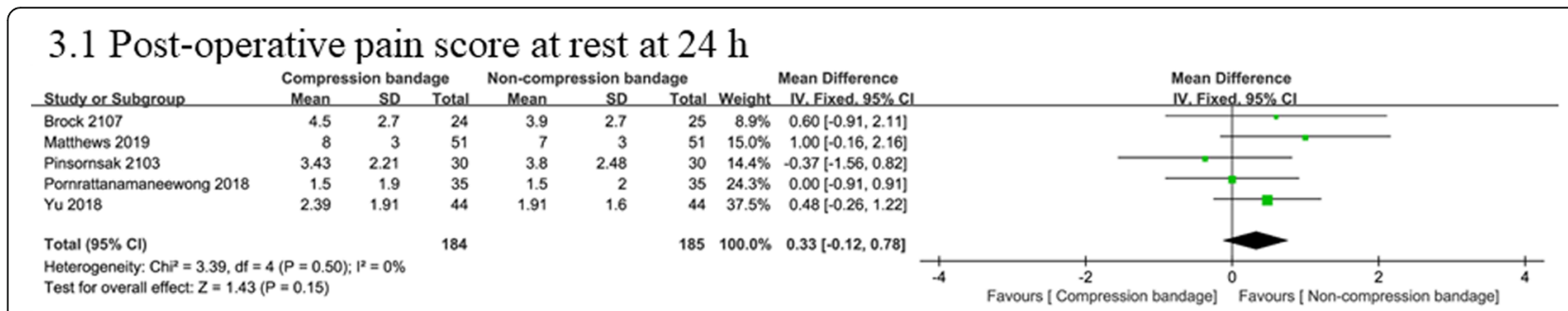

\subsection{Post-operative pain score at rest at $48 \mathrm{~h}$}

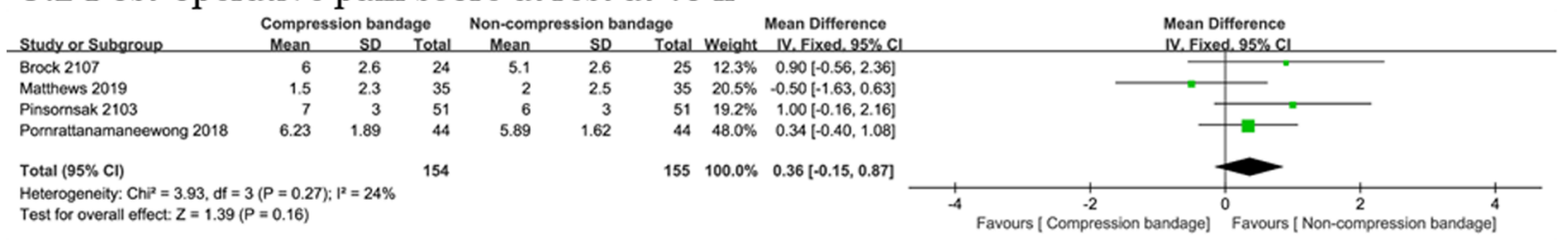

\subsection{Post-operative pain score during ambulation at $24 \mathrm{~h}$}

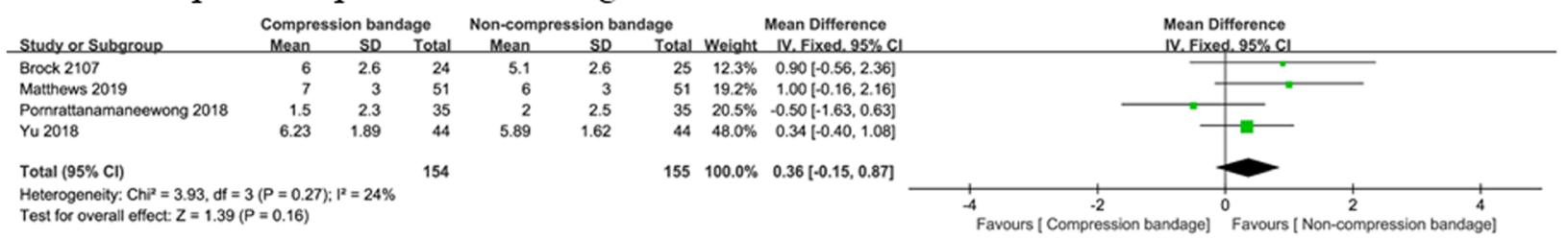

\subsection{Post-operative pain score during ambulation at $48 \mathrm{~h}$}

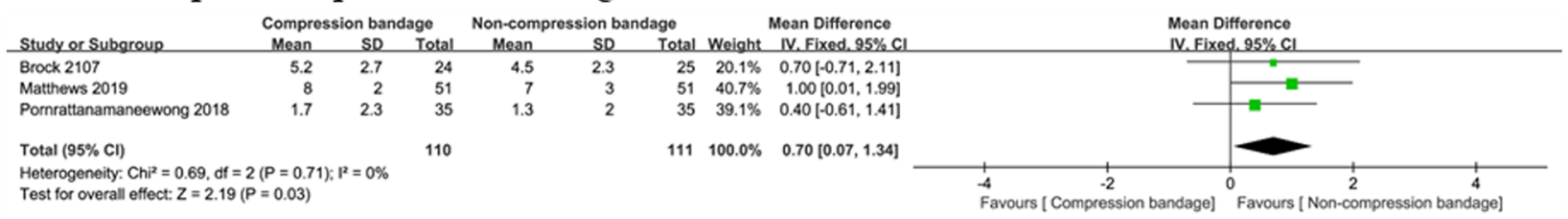

Fig. 3 Forest plots of the included studies comparing post-operative pain

post-operative pain scores during ambulation at $48 \mathrm{~h}$. It was found that there was no significant difference in regard to post-operative pain at the other times, swelling, blood loss, ROM, or complications between the two groups.

The use of compression bandages as a posttraumatic and post-operative bandage has been recommended to protect soft tissues and knee reconstruction surgery, with the therapy previously having shown positive effects in the treatments of venous ulcers and lymphedema $[22,23]$. However, the potential benefits in TKA remain debatable due to conflicting results in the literature. Brodell et al. [9] showed that compression bandage could generate and sustain external compression to the soft tissues over the limb for at least $24 \mathrm{~h}$, where the pressure was between 40 and $50 \mathrm{mmHg}$ at initial application, decreasing to 2 to $10 \mathrm{mmHg}$ within $48 \mathrm{~h}$. Of which theoretically, aids venous reflux and reduces hydrostatic pressure after TKA when compared to noncompression bandage.
From previous studies, compression bandages were thought to help decrease post-operative pain [24]. Conversely, we found that post-operative pain during ambulation at $48 \mathrm{~h}$ in the non-compression bandages group was actually lower than in the compression bandages group $(P=0.03)$. The difference was statistically significant; however, it was not clinically relevant. Brock et al. also found a small increase in postoperative pain score in the compression bandages group at 24 and $48 \mathrm{~h}$, but without a significant difference [15]. A meta-analysis including 199 knees that underwent compression bandages and 203 knees that underwent non-compression bandages concluded that there was no significant difference in post-operative pain scores [25].

Matthews et al. compared the application of an elastic compression bandage versus no bandage after TKA. They found no difference in knee swelling between the two groups, which neither benefited nor harmed the patients. Thus, they no longer use elastic compression bandage routinely for primary TKA 


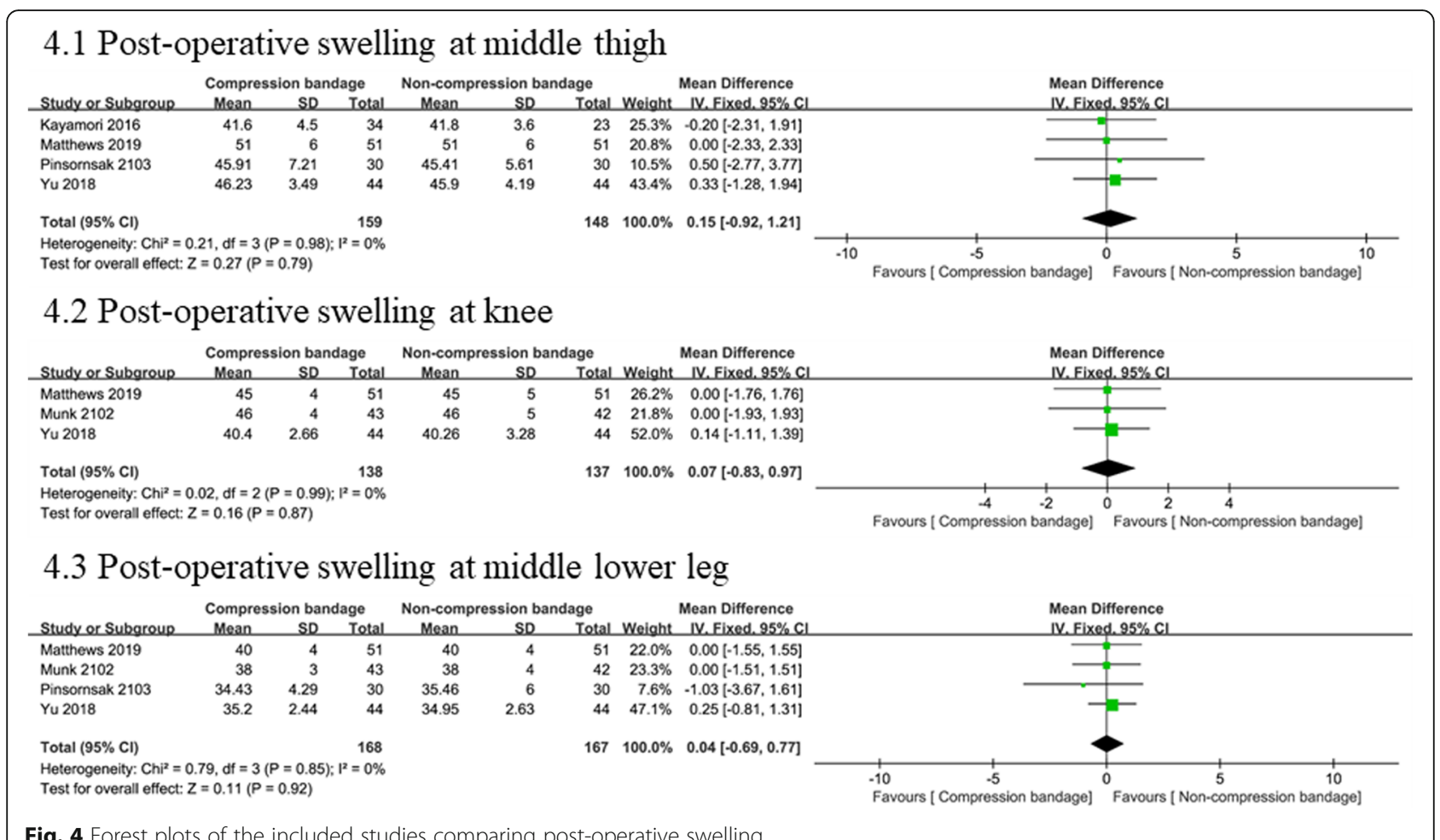

Fig. 4 Forest plots of the included studies comparing post-operative swelling

[19]. Conversely, Pichonnaz et al. noted massive swelling after TKA within the first 2 days without using of compression bandage [26]. Our metaanalysis found no significant difference in postoperative swelling whether using the compression bandage or not. Thus, it is thought that the results of post-operative swelling may be influenced by both the method used to measure and tester. In clinical trials, swelling was usually measured by a tape, where measurement errors may occur between intra- tester and inter-tester which were reported by Jakobsen [27]. Evaluating post-operative swelling is also limited by the measurement technique. A prospective randomized study involving 19 patients with knee arthroscopy was reported by Tischer, and stated that optoelectronic measurements indicated high reliability [3].

It has been hypothesized that the use of compression bandages could have a tamponade effect and help reduce blood loss [4]. Pinsornsak et al. performed a RCT including 60 participants, and reported

\subsection{Total blood loss}

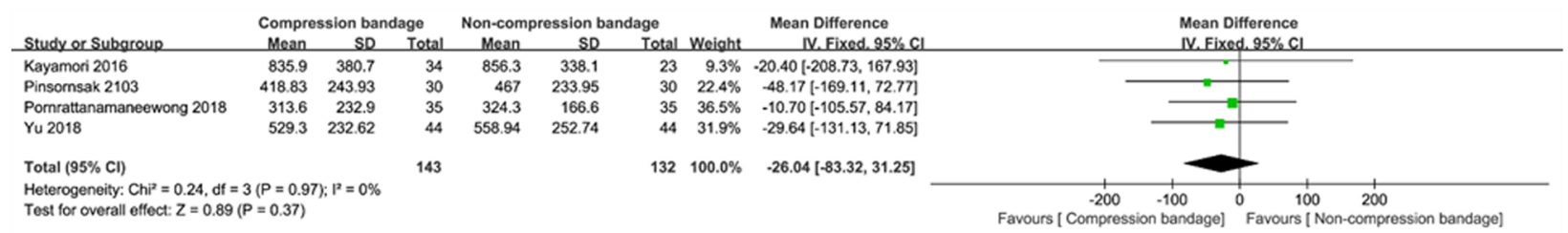

\subsection{Pre- and post-operative hematocrit levels differences}

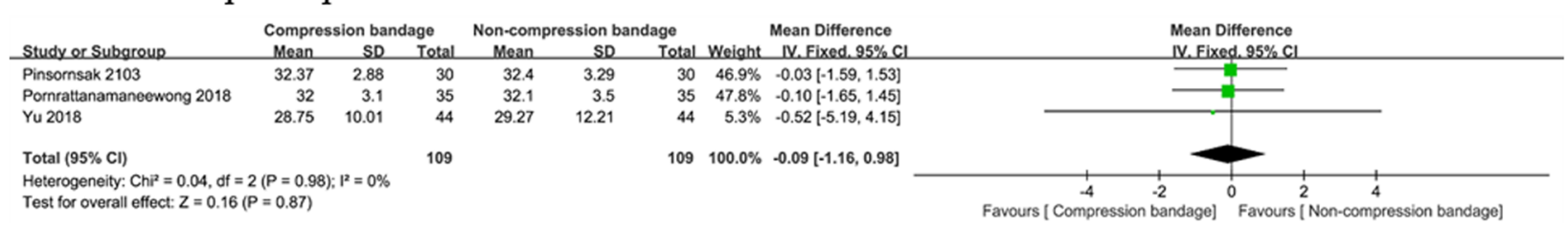

Fig. 5 Forest plots of the included studies comparing blood loss 


\begin{tabular}{|c|c|c|c|c|c|c|c|c|c|c|c|}
\hline \multirow[b]{2}{*}{ Study or Subgroup } & \multicolumn{3}{|c|}{ Compression bandage } & \multicolumn{3}{|c|}{ Non-compression bandage } & & \multirow{2}{*}{$\begin{array}{l}\text { Mean Difference } \\
\quad \text { IV. Fixed, } 95 \% \mathrm{Cl}\end{array}$} & \multirow{2}{*}{\multicolumn{3}{|c|}{ Mean Difference }} \\
\hline & Mean & SD & Total & Mean & SD & Total & Weight & & IV. Fixe & & \\
\hline Kayamori 2016 & 62.3 & 14.5 & 34 & 60.2 & 10 & 23 & $32.7 \%$ & $2.10[-4.26,8.46]$ & & 10 & \\
\hline Matthews 2019 & 68 & 32 & 51 & 70 & 29 & 51 & $9.4 \%$ & $-2.00[-13.85,9.85]$ & & & \\
\hline Yu 2018 & 84.9 & 10 & 35 & 85.3 & 10.4 & 35 & $57.9 \%$ & $-0.40[-5.18,4.38]$ & & & \\
\hline Total $(95 \% \mathrm{Cl})$ & & & 120 & & & 109 & $100.0 \%$ & $0.27[-3.37,3.90]$ & & & \\
\hline \multicolumn{4}{|c|}{$\begin{array}{l}\text { Heterogeneity: } \mathrm{Chi}^{2}=0.53, \mathrm{df}=2(P=0.77) ; 1^{2}=0 \% \\
\text { Test for overall effect: } Z=0.14(P=0.89)\end{array}$} & & & & & & $\begin{array}{ll}-20 & -10 \\
\text { Favours [ Compression bandage] }\end{array}$ & ${ }^{0}$ Favours [ & $\begin{array}{cc}10 & 20 \\
\text { Non-compression bandage] }\end{array}$ \\
\hline
\end{tabular}

that the modified Robert Jones bandage tended to reduce blood loss by $46 \mathrm{~mL}$ compared with the conventional dressing during the first 24h [13]. However, Gibbons et al. reported that the modified Robert Jones bandage group was associated with more blood loss than the control group using conventional dressing (1200 mL versus $720 \mathrm{~mL}$, respectively) [28]. In our meta-analysis, blood loss was evaluated via total blood loss and pre- and post-operative hematocrit levels differences. Pooled results showed that the application of compression bandages did not result in a significant reduction of blood loss following TKA. Many studies agree with our findings in term of blood loss $[20,25]$, therefore these results combined indicate that the pressure from compression bandages is not enough to control intra-articular bleeding effectively.

Brock et al. [15] and Kayamori et al. [21] both found no differences in post-operative knee ROM in their studies. Brock reported that ROM values were close to preoperative levels by 6 weeks after TKA [15], and a similar result was found in our meta-analysis. In contrast, Cheung et al. found improved flexion ROM and ability to straight leg raise at discharge when comparing cohesive inelastic compression bandage versus standard crepe bandage [11]. Charalambides et al. reported shorter length of stay and greater ROM on discharge when a compression bandage was used [4]. However, these studies had weaknesses in the design of retrospective data in the cohort.

Our meta-analysis demonstrates that compression bandages can be carried out safely after TKA without difference in complications between the both groups. Yu et al. found a significantly lower patient comfort level in the compression group during the first post-operative $24 \mathrm{~h}$ [14], and his finding agreed with Ramelet's study, where compression therapy was related to poor patient compliance [29]. Reasons for not using compression therapy included that the bandage induced discomfort such as "cutting off" of circulation, "too hot" to wear, limb distress, poor cosmetic appearance, contact dermatitis, and itching [30].

This meta-analysis is not without limitations, and these should be acknowledged. First, only seven RCTs involving 511 patients were selected, and the limited sample sizes have weakened the objective evaluation. Second, the compression bandage techniques utilized in each RCT were not uniform. Compression bandages have different shapes, consistencies, thicknesses, and sub-bandage pressure, which may cause bias. Third, publication bias is unescapable due to the published language being identified as English. Fourth, the varied follow-up term will introduce heterogeneities, and longer-term follow-up was necessary. Finally, the included studies used different rehabilitation schemes, which could also have affected outcomes. This metaanalysis did not estimate these factors, and further evaluation is necessary in future studies.

\section{Conclusion}

Based on this meta-analysis, we found that the outcomes between the use of a compression bandages and noncompression bandages after TKA are comparable, which neither benefit nor harm the patient. However, improvements in future meta-analysis in this area should consider larger sample sizes and high quality research to identify the validity in future.

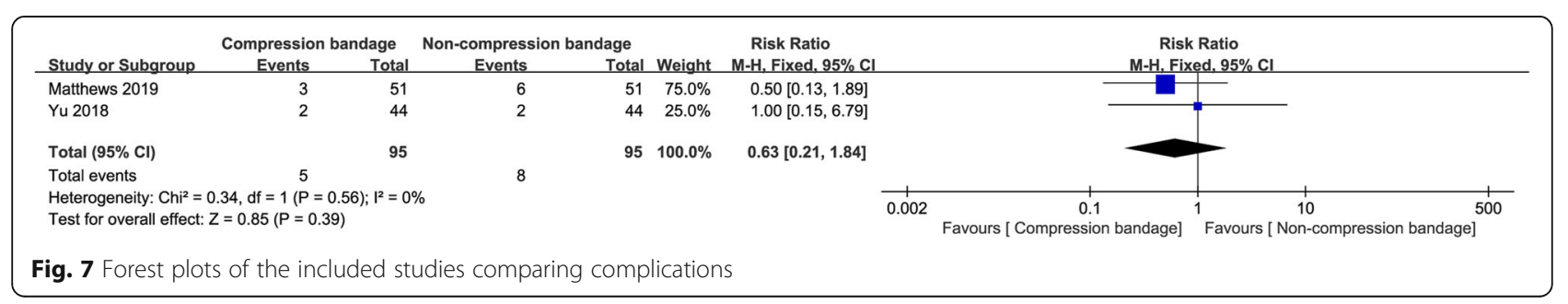




\section{Supplementary information}

Supplementary information accompanies this paper at https://doi.org/10. 1186/s13018-019-1527-9.

Additional file 1. Raw data.

\section{Abbreviations}

$\mathrm{Cl}$ : Confidence intervals; GRADE: Grading of Recommendations Assessment, Development, and Evaluation; KOA: Knee osteoarthritis; KSS: Knee Society Score; OA: Osteoarthritis; PRISMA: Preferred Reporting Items for Systematic Reviews and Meta-analyses; RCT: Randomized controlled trials; ROM: Range of motion; RR: Relative ratios; TKA: Total knee arthroplasty; VAS: Visual analogue scale; WMD: Weighted mean differences

\section{Acknowledgments}

We thank Rebecca Tollefson, DVM, from Liwen Bianji, Edanz Editing China (www. liwenbianji.cn/ac), for editing the English text of a draft of this manuscript.

\section{Authors' contributions}

All authors listed have made contributions to the meta-analysis. PL and WW designed the study. PL, XM, and WW participated in performing the review and collecting the data. QZ and ZL took part in analyzing the data. PL, WW, and WG wrote and revised the manuscript. All authors read and approved the final manuscript.

\section{Funding}

This study was funded by the National Natural Science Foundation of China (grant number 81703896, 81673776), the Capital Health Research and Development of Special (grant number 2016-2-4062), Beijing municipal science and technology commission (grant number Z171100001017209), and National Key Research and Development Program of China (grant number 2017YFC0108102).

\section{Availability of data and materials}

The datasets generated during and/or analyzed during the current study are available from the corresponding author on reasonable request.

\section{Ethics approval and consent to participate}

This study dealt with published data only, no ethical approval was needed.

\section{Consent for publication}

Not applicable.

\section{Competing interests}

The authors declare that they have no competing interests.

\section{Author details}

${ }^{1}$ Beijing University of Chinese Medicine, Yinghuadong Road, Chaoyang District, Beijing, China. ${ }^{2}$ Department Orthopedics 4, Beijing University of Chinese Medicine, Dongzhimen Hospital, Beijing, China. ${ }^{3}$ Department of Orthopaedic Surgery, Beijing Key Lab Immune-Mediated Inflammatory Diseases, China-Japan Friendship Hospital, Yinghuadong Road, Chaoyang District, Beijing, China.

Received: 28 September 2019 Accepted: 18 December 2019 Published online: 14 February 2020

\section{References}

1. Carr AJ, Robertsson O, Graves S, Price AJ, Arden NK, Judge A, et al. Knee replacement. Lancet. 2012;379:1331-40. https://doi.org/10.1016/S01406736(11)60752-6.

2. Kijkunasathian C, Limitlaohaphan C, Saengpetch N, Chanasit P, Sundarathit P, Waratanarat P. A comparison between modified Robert Jones bandage and intermittent cold pack in arthroscopic anterior cruciate ligament reconstruction: a prospective randomized controlled trial. J Med Assoc Thail. 2017; 100:287-94.

3. Tischer TS, Oye S, Lenz R, Kreuz P, Mittelmeier W, Bader R, et al. Impact of compression stockings on leg swelling after arthroscopy-a prospective randomised pilot study. BMC Musculoskelet Disord. 2019;20 https://doi.org/ 10.1186/s12891-019-2540-1.
4. Charalambides C, Beer M, Melhuish J, Williams RJ, Cobb AG. Bandaging technique after knee replacement. Acta Orthop. 2005;76:89-94. https://doi. org/10.1080/00016470510030382.

5. Song M, Sun $X$, Tian $X$, Zhang $X$, Shi $T$, Sun $R$, et al. Compressive cryotherapy versus cryotherapy alone in patients undergoing knee surgery: a meta-analysis. Springerplus. 2016;5:1074. https://doi.org/10.1186/s40064016-2690-7.

6. Rama KR, Apsingi S, Poovali S, Jetti A. Timing of tourniquet release in knee arthroplasty. Meta-analysis of randomized, controlled trials. J Bone Joint Surg Am. 2007;89:699-705. https://doi.org/10.2106/JBJS.F.00497.

7. Heller S, Chen A, Restrepo C, Albert E, Hozack WJ. Tourniquet release prior to dressing application reduces blistering following total knee arthroplasty. J Arthroplast. 2015;30:1207-10. https://doi.org/10.1016/j.arth.2015.02.035.

8. Ishida K, Tsumura N, Kitagawa A, Hamamura S, Fukuda K, Dogaki Y, et al. Intra-articular injection of tranexamic acid reduces not only blood loss but also knee joint swelling after total knee arthroplasty. Int Orthop. 2011;35: 1639-45. https://doi.org/10.1007/s00264-010-1205-3.

9. Brodell JD, Axon DL, Evarts CM. The Robert Jones bandage. J Bone Joint Surg (Br). 1986;68:776-9.

10. Stocker B, Babendererde C, Rohner-Spengler M, Muller UW, Meichtry A, Luomajoki $\mathrm{H}$. Effective therapy to reduce edema after total knee arthroplasty multi-layer compression therapy or standard therapy with cool pack - a randomized controlled pilot trial. Pflege. 2018;31:19-29. https://doi. org/10.1024/1012-5302/a000575.

11. Cheung A, Lykostratis $\mathrm{H}$, Holloway I. Compression bandaging improves mobility following total knee replacement in an enhanced recovery setting. J Perioper Pract. 2014;24:84-6. https://doi.org/10.1177/175045891602400405.

12. Smith J, Stevens J, Taylor M, Tibbey J. A randomized, controlled trial comparing compression bandaging and cold therapy in postoperative total knee replacement surgery. Orthop Nurs. 2002;21:61-6.

13. Pinsornsak P, Chumchuen S. Can a modified Robert Jones bandage after knee arthroplasty reduce blood loss? A prospective randomized controlled trial. Clin Orthop Relat Res. 2013;471:1677-81. https://doi.org/10.1007/ s11999-013-2786-0.

14. Yu H, Wang H, Zhou K, Rong X, Yao S, Pei F, et al. Modified Robert Jones bandage can not reduce postoperative swelling in enhanced-recovery after primary total knee arthroplasty without intraoperative tourniquet: a randomized controlled trial. BMC Musculoskelet Disord. 2018;19:357. https:// doi.org/10.1186/s12891-018-2281-6.

15. Brock TM, Sprowson AP, Muller S, Reed MR. STICKS study - short-sTretch inelastic compression bandage in knee swelling following total knee arthroplasty - a feasibility study. Trials. 2017;18:6. https://doi.org/10.1186/ s13063-016-1767-5.

16. Nazarko L. Simplifying the management of venous leg ulcers: choosing appropriate and acceptable compression therapy. Br J Community Nurs. 2017;22:S6-12. https://doi.org/10.12968/bjcn.2017.22.Sup6.S6.

17. Keller A, Muller ML, Calow T, Kern IK, Schumann H. Bandage pressure measurement and training: simple interventions to improve efficacy in compression bandaging. Int Wound J. 2009;6:324-30. https://doi.org/10. 1111/j.1742-481X.2009.00621.x.

18. Munk S, Jensen NJ, Andersen I, Kehlet H, Hansen TB. Effect of compression therapy on knee swelling and pain after total knee arthroplasty. Knee Surg Sports Traumatol Arthrosc. 2013;21:388-92. https://doi.org/10.1007/s00167012-1963-0.

19. Matthews CN, Chen AF, Daryoush T, Rothman RH, Maltenfort MG, Hozack WJ. Does an elastic compression bandage provide any benefit after primary TKA? Clin Orthop Relat Res. 2019;477:134-44. https://doi.org/10.1097/CORR. 0000000000000459

20. Pornrattanamaneewong C, Ruangsomboon P, Chareancholvanich K, Wilairatana V, Narkbunnam R. Modified Robert Jones bandage can not reduce invisible blood loss after total knee arthroplasty: a randomizedcontrolled trial. Arch Orthop Trauma Surg. 2018;138:1151-7. https://doi.org/ 10.1007/s00402-018-2978-x

21. Kayamori S, Tsukada S, Sato M, Komata K, Isida Y, Wakui M. Impact of postoperative compression dressing using polyethylene foam pad on the multimodal protocol for swelling control following total knee arthroplasty: a randomized controlled trial. Arthroplast Today. 2016;2:199-204. https://doi. org/10.1016/j.artd.2016.05.004.

22. Pike C. Using Actico bandaging for chronic oedema/lymphoedema management. Br J Nurs. 2011;20:1246-8-51. https://doi.org/10.12968/bjon. 2011.20.19.1246. 
23. Franks PJ, Moody M, Moffatt CJ, Martin R, Blewett R, Seymour E, et al. Randomized trial of cohesive short-stretch versus four-layer bandaging in the management of venous ulceration. Wound Repair Regen. 2004;12:157-62. https://doi.org/10.1111/j.1067-1927.2004.012206.x.

24. Andersen LO, Husted H, Otte KS, Kristensen BB, Kehlet H. A compression bandage improves local infiltration analgesia in total knee arthroplasty. Acta Orthop. 2008;79:806-11. https://doi.org/10.1080/17453670810016894.

25. Feng $X$, Zhao G, Yan Q. The efficacy and safety of modified Robert Jones bandage in total knee arthroplasty: a meta-analysis of randomized-controlled trials. Int J Surg. 2019;63:22-33. https://doi.org/10.1016/j.jisu.2019.01.015.

26. Pichonnaz C, Bassin JP, Lecureux E, Currat D, Jolles BM. Bioimpedance spectroscopy for swelling evaluation following total knee arthroplasty: a validation study. BMC Musculoskelet Disord. 2015;16:100. https://doi.org/10. 1186/s12891-015-0559-5.

27. Jakobsen TL, Christensen M, Christensen SS, Olsen M, Bandholm T. Reliability of knee joint range of motion and circumference measurements after total knee arthroplasty: does tester experience matter? Physiother Res Int. 2010; 15:126-34. https://doi.org/10.1002/pri.450.

28. Gibbons CE, Solan MC, Ricketts DM, Patterson M. Cryotherapy compared with Robert Jones bandage after total knee replacement: a prospective randomized trial. Int Orthop. 2001;25:250-2. https://doi.org/10.1007/ s002640100227.

29. Ramelet AA. Compression therapy. Dermatol Surg. 2002;28:6-10. https://doi. org/10.1046/j.1524-4725.2002.01181.x

30. Raju S, Hollis K, Neglen P. Use of compression stockings in chronic venous disease: patient compliance and efficacy. Ann Vasc Surg. 2007;21:790-5. https://doi.org/10.1016/j.avsg.2007.07.014.

\section{Publisher's Note}

Springer Nature remains neutral with regard to jurisdictional claims in published maps and institutional affiliations.

Ready to submit your research? Choose BMC and benefit from:

- fast, convenient online submission

- thorough peer review by experienced researchers in your field

- rapid publication on acceptance

- support for research data, including large and complex data types

- gold Open Access which fosters wider collaboration and increased citations

- maximum visibility for your research: over $100 \mathrm{M}$ website views per year

At BMC, research is always in progress.

Learn more biomedcentral.com/submissions 